\title{
Penetapan Metode SMART dalam Merekomendasikan Jenis Sapi Terbaik untuk Peternakan Sapi Potong
}

\author{
Gumilar Ramadhan Pangaribuan', Yovan Bastian², Eka Irawan ${ }^{3}$ \\ STIKOM Tunas Bangsa Pematangsiantar \\ Jl. Jenderal Sudirman Blok A No.1/2/3 Pematangsiantar, Medan, Indonesia, 21127 \\ Email : gumilaramadhan97@gmail.com¹, yovanbastian@gmail.com², \\ eka.irawan@amiktunasbangsa.ac.id ${ }^{3)}$
}

\begin{abstract}
The Livestock Sector is one of the most promising agribusiness sectors. The selection of the right type of cow is the duty of cattle farmers to get cows with good quality and greatly affect the success in raising cattle. Decision support system is a system that is able to provide a picture of the decision of the existing situation. And this system is applied to cattle farms to determine the best type of cow for the smooth running of the farm business. The method used is SMART. The samples used were 6 types of cattle and the assessment criteria in the selection of cattle were: Origin, Price, Age, Weight, and Size. The results of this study were the selection of Lemosin cattle as the best type of cattle for beef cattle farming. SPK in Cattle Purchases for Breeding is only a recommendation to the farmer, for the next process to be returned to the farmer.
\end{abstract}

Keyword: Beef Cattle; SMART; SPK

Abstrak- Sektor Peternakan merupakan salah satu sektor agrobisnis yang sangat menjanjikan. Pemilihan Jenis Sapi yang tepat adalah tugas dari peternak sapi untuk mendapatkan sapi dengan kualitas yang baik dan sangat mempengaruhi keberhasilan dalam berternak sapi. Sistem pendukung keputusan merupakan suatu sistem yang mampu memberikan suatu gambaran keputusan dari keadaan yang ada. Dan sistem ini di terapkan pada usaha peternakan sapi untuk menentukan jenis sapi terbaik demi kelancaran usaha peternakan tersebut. Metode yang digunakan adalah SMART. Adapun sample yang digunakan sebanyak 6 jenis sapi dan kriteria penilaian dalam pemilihan sapi yaitu : Asal, Harga, Usia, Bobot, dan Ukuran. Hasil dari penelitian ini adalah terpilihknya sapi Lemosin sebagai jenis sapi terbaik untuk peternakan sapi potong. SPK Dalam Pembelian Sapi untuk Diternakkan hanya bersifat memberikan rekomendasi keputusan kepada pihak peternak, untuk proses selanjutnya diserahkan kembali kepada pihak peternak.

Kata kunci: Sapi Potong ; SMART; SPK

\section{PENDAHULUAN}

Sapi potong adalah sapi yang dipelihara dengan tujuan utama sebagai penghasil daging, sehingga sering disebut sebagai sapi pedaging[1]. Laju peningkatan populasi sapi potong relatif lamban, kondisi tersebut menyebabkan sumbangan sapi potong terhadap produksi daging nasional rendah sehingga terjadi kesenjangan yang makin lebar antara permintaan dan penawaran. Banyak sekali peternak sapi potong yang gagal dalam bisnis nya karena tidak dapat memilih jenis sapi terbaik yang cocok di ternakkan. Untuk mencapai efisiensi usaha yang tinggi di perlukan pengolahan usaha secara terintegrasi dari hulu hingga hilir serta terorientasi agribisnis dengan pola kemitraan, sehingga dapat 
memberikan keuntungan yang layak secara berkelanjutan. Bisnis sapi potong yang berkembang pesat saat ini, menimbulkan persaingan yang sangat tajam dalam memenuhi pasokan daging sapi.

Bisnis sapi potong yang berkembang pesat saat ini, menimbulkan persaingan yang sangat tajam dalam memenuhi pasokan daging sapi. Diindonesia banyak sekali jenis sapi dengan berbagai jenis yang tersebar luas. Hal ini menyebabkan peternak harus benar-benar teliti dalam memilih jenis sapi untuk di ternakkan. Penelitian ini bertujuan untuk mempermudah pengusuha peternakan sendiri dalam memilih jenis sapi terbaik untuk usaha nya berdasarkan kriteria - kriteria yang telah di tentukan. Dalam memberikan rekomendasi jenis sapi terbaik, peternak sapi harus dapat mengetahui jenis sapi mana yang memiliki kualitas unggul untuk menghasilkan sapi dengan kualitas terbaik. Sehingga peternak mendapatkan keuntungan yang lebih besar. Penelitian terdahulu yang berkaitan dengan metode SMART adalah tentang Pemilihan Cafe[2] , Pengukuran Kinerja Perusahaan[3], Merekomendasikan Peserta UKK Jurusan TKJ[4], Menentukan Jurusan Pada Siswa Sma[5] dan Pemilihan Mobil [6].Pada penilitian ini dilakukan di AMIK dan STIKOM Tunas Bangsa Pematangsiantar. Hasil penilaian harus dievaluasi berdasarkan kriteria-kriteria yang sudah ditentukan oleh pihak kemahasiswaan dalam memilih mahasiswa sebagai leader official (pembimbing) dalam Perkenalan Kehidupan Kampus Mahasiswa Baru (PKKMB).

\section{METODOLOGI PENELITIAN}

Proses penelitian dimulai dari studi literatur, yaitu mencari referensi dari berbagai sumber, kemudian melakukan pengumpulan data yang diperlukan dalam penelitian, data yang telah didapat selanjutnya dianalisis untuk digunakan sebagai masukan. Langkah selanjutnya yaitu melakukan perancangan dengan membuat rincian perhitungan dengan metode SMART (Simple Multi Attribute Rating Technique), hal ini dilakukan untuk mengetahui sistem yang dibuat sudah sesuai harapan atau belum. Tahap akhir dari penelitian ini adalah penarikan kesimpulan yang menyatakan bahwa hasil dari metode ini efektif dalam penunjang keputusan.

\subsection{Sistem Pendukung Keputusan}

Sistem Pendukung Keputusan (SPK) atau Decision Support System (DSS) adalah sebuah sistem yang mampu memberikan kemampuan pemecahan masalah maupun kemampuan pengkomunikasian untuk masalah dengan kondisi semi terstruktur dan tak terstruktur. Sistem ini digunakan untuk membantu pengambilan keputusan dalam situasi semi terstruktur dan situasi yang tidak terstruktur, di mana tak seorangpun tahu secara pasti bagaimana keputusan seharusnya dibuat [7]. Dapat disimpulkan bahwa, Sistem Pendukung Keputusan adalah sebuah sistem yang mendukung kerja seorang manager maupun sekelompok manager dalam memecahkan masalah semi-terstruktur dengan cara memberikan informasi ataupun usulan menuju pada keputusan tertentu [8]-[18].

\subsection{Metode SMART}

SMART (Simple Multi - Attribut Rating Technique) merupakan metode pengambilan keputusan multi kriteria yang dikembangkan oleh Edward pada 
tahun 1997. Teknik pengambilan keputusan multi kriteria ini didasarkan pada teori bahwa setiap alternatif terdiri dari sejumlah kriteria yang memiliki nilai-nilai dan setiap kriteria memiliki bobot yang menggambarkan seberapa penting dibandingkan dengan kriteria lain. Pembobotan ini digunakan untuk menilai setiap alternatif agar diperoleh alternatif terbaik. SMART merupakan metode dalam pengambilan keputusan multiatribut. Teknik pengambilan keputusan multiatribut ini digunakan untuk mendukung pembuat keputusan dalam memilih beberapa alternatif. Setiap pembuat keputusan harus memiliki sebuah alternatif yang sesuai dengan tujuan yang dirumuskan. Setiap alternatif terdiri dari sekumpulan atribut dan setiap atribut mempunyai nilai-nilai. Nilai ini dirata-rata dengan skala tertentu. Setiap atribut mempunyai bobot yang menggambarkan seberapa penting suatu atribut dibandingkan dengan atribut lain. Pembobotan dan pemberian peringkat ini digunakan untuk menilai setiap alternatif agar diperoleh alternatif terbaik [19].SMART menggunakan linear additive model untuk meramal nilai setiap alternatif. SMART merupakan metode pengambilan keputusan yang fleksibel. SMART lebih banyak digunakan karena kesederhanaanya dalam merespon kebutuhan pembuat keputusan dan caranya menganalisa respon. Analisa yang terlibat adalah transparan sehingga metode ini memberikan pemahaman masalah yang tinggi dan dapat diterima oleh pembuat keputusan.

\subsection{Proses Pemodelan Metode SMART}

Urutan dalam penggunaan metode SMART ( Goodwin dan Wright, 2004) adalah sebagai berikut :

a. Menentukan banyaknya kriteria digunakan.

b. Menentukan bobot kriteria pada masing- masing kriteria dengan menggunakan interval 1-100 untuk masing-masing kriteria dengan prioritas terpenting.

c. Hitung normalisasi dari setiap kriteria dengan membandingkan nilai bobot kriteria dengan jumlah bobot kriteria.Menggunakan rumus :

Normalisasi :

$$
\frac{\boldsymbol{W} \boldsymbol{j}}{\sum \boldsymbol{W} \boldsymbol{j}}
$$

Dimana $\boldsymbol{W} \boldsymbol{j}$ adalah nilai bobot dari suatu kriteria. Sedangkan, $\sum \boldsymbol{W} \boldsymbol{j}$ adalah total jumlah bobot dari semua kriteria.

d. Memberikan nilai parameter kriteria pada setiap kriteria untuk setiap alternatif.

e. Menentukan nilai utiliti denganmengonversikan nilai kriteria pada masingmasing kriteria menjadi nilai kriteria data baku. Nilai utiliti diperoleh dengan menggunakan persamaan :

$$
u_{i}\left(a_{i}\right)=\frac{C_{o u t}-C_{\min }}{C_{\max }-C_{\min }}
$$

Dimana $\boldsymbol{u}_{\boldsymbol{i}}\left(\boldsymbol{a}_{\boldsymbol{i}}\right)$ adalah nilai utiliti kriteria ke-1 untuk kriteria ke - I, $\boldsymbol{C}_{\boldsymbol{m a x}}$ adalah nilai kriteria maksimal, $\boldsymbol{C}_{\boldsymbol{m i n}}$ adalah nilai kriteria minimal dan $\boldsymbol{C}_{\boldsymbol{o u t}} \boldsymbol{t}^{\boldsymbol{i}}$ adalah nilai kriteria ke- i. Maka didapat nilai tersebut adalah :

$$
C_{\text {out }}{ }=u_{i}\left(a_{i}\right), 1=0 ; 2=0,5: 3=1
$$

f. Menentukan nilai akhir dari masing- masing kriteria dengan mengalihkan nilai yang didapat dari normalisasi nilai kriteria data baku dengan nilai normalisasi bobot kriteria. Kemudian jumlahkan nilai dari perkalian tersebut.

$$
\boldsymbol{u}\left(\boldsymbol{a}_{\boldsymbol{i}}\right)=\sum_{J=i}^{m} \boldsymbol{W}_{j} \boldsymbol{u}_{\boldsymbol{i}}\left(\boldsymbol{a}_{\boldsymbol{i}}\right)
$$

Metode SMART dalam Merekomendasikan Jenis Sapi Terbaik (Gumilar Ramadhan Pangaribuan)|223 
Dimana $\boldsymbol{u}\left(\boldsymbol{a}_{\boldsymbol{i}}\right)$ adalah nilai total alternatif, $\boldsymbol{W}_{\boldsymbol{j}}$ adalah hasil dari normalisasi bobot kriteria dan $\boldsymbol{u}_{\boldsymbol{i}}\left(\boldsymbol{a}_{\boldsymbol{i}}\right)$ adalah hasil penentuan nilai utiliti.

\section{HASIL DAN PEMBAHASAN}

\subsection{Analisis Perhitungan Metode SMART}

Dalam penerapan metode SMART untuk penentuan jenis sapi terbaik ada beberapa hal yang perlu dilakukan sebelum melakukan perhitungan nilai, salah satunya yaitu :

a. Identifikasi kriteria

Dalam sistem penilaian ada 5 kriteria yang didapatkan melalui hasil wawancara dengan peternak sapi yaitu asal, harga, usia, bobot, dan ukuran.

b. Pemberian bobot kriteria

Pemberian bobot kriteria didapat melalui hasil wawancara penilaian dan berdasarkan pada pemberian bobot terbesar hingga bobot terkecil dengan interval 1-100 dan dijadikan nilai default pada sistem. Kemudian semua nilai tersebut dijumlahkan.

Tabel 1. Bobot Kriteria

\begin{tabular}{|c|c|c|}
\hline No & Kriteria & Bobot \\
\hline 1 & Asal & 10 \\
\hline 2 & Harga & 10 \\
\hline 3 & Usia & 20 \\
\hline 4 & Bobot & 50 \\
\hline 5 & Ukuran & 10 \\
\hline \multicolumn{2}{|r|}{ Total } & 100 \\
\hline
\end{tabular}

Setelah di dapatkan nilai untuk setiap kriteria, kemudian di lakukan normalisasi, yaitu dengan membagi antara antara nilai bobot kriteria dengan jumlah nilai menggunakan persamaan (1).

Tabel 2. Normalisasi Bobot Kriteria

\begin{tabular}{|c|c|c|c|}
\hline No & Kriteria & Bobot Kriteria & $\begin{array}{c}\text { Normalisasi } \\
\text { Bobot } \\
\text { Kriteria }\end{array}$ \\
\hline 1 & Asal & $10 / 100$ & 0,1 \\
\hline 2 & Harga & $10 / 100$ & 0,1 \\
\hline 3 & Usia & $20 / 100$ & 0,2 \\
\hline 4 & Bobot & $50 / 100$ & 0,5 \\
\hline 5 & Ukuran & $10 / 100$ & 0,1 \\
\hline
\end{tabular}

c. nilai kriteria pada semua alternatif.

Nilai tersebut bisa dilihat pada tabel 3.

Tabel 3. Pemberian Nilai Kriteria

\begin{tabular}{|c|c|c|c|c|c|c|}
\hline \multirow{2}{*}{ No } & \multirow{2}{*}{ Alternatif } & \multicolumn{5}{|c|}{ Kriteria } \\
\cline { 3 - 7 } & & Asal & Harga & Usia & Bobot & Ukuran \\
\hline 1 & Lemosin & 0,9 & 45 & 37 & 1100 & 1,5 \\
\hline 2 & Simental & 0,8 & 17 & 24 & 460 & 1 \\
\hline 3 & Bali & 0,7 & 25 & 35 & 900 & 1,3 \\
\hline
\end{tabular}




\begin{tabular}{|c|c|c|c|c|c|c|}
\hline 4 & Perah & 0,6 & 10 & 36 & 250 & 1 \\
\hline 5 & Brahma & 0,9 & 15 & 12 & 310 & 1,1 \\
\hline 6 & Madras & 0,7 & 18 & 37 & 500 & 1,1 \\
\hline
\end{tabular}

Nilai-nilai kriteria tersebut kemudian dikonversikan menjadi sebuah nilai kriteria data baku untuk menentukan nilai utiliti yang didapat dari persamaan(2). Bisa dilihat pada tabel 4 Asal ,Harga ,Usia ,Bobot dan Ukuran untuk masingmasing usaha dihitung berdasarkan persamaan (2).

Maks(Asal) $\quad=\operatorname{maks}\{0.9,0.8,0.7,0.6,0.9,0.7\}=0.9 \operatorname{Min}($ Asal $)=\min$ $\{0.9,0.8,0.7,0.6,0.9,0.7\}=0.6$ Sehingga :

Lemosin(Asal) $=\left(\frac{0.9-0.6}{0.9-0.6}\right) * 100 \%=1$

Simental(Asal) $=\left(\frac{0.8-0.6}{0.9-0.6}\right) * 100 \%=0,666667$

Bali(Asal) $\quad=\left(\frac{0.7-0.6}{0.9-0.6}\right) * 100 \%=0,333333$

Perah(Asal) $\quad=\left(\frac{0.6-0.6}{0.9-0.6}\right) * 100 \%=0$

Brahma(Asal) $=\left(\frac{0.9-0.6}{0.9-0.6}\right) * 100 \%=1$

Madras(Asal) $=\left(\frac{0.7-0.6}{0.9-0.6}\right) * 100 \%=0,333333$

Nilai Harga dihitung dengan persamaan 2. Maks(Harga)=45 Min(Harga)=10

Sehingga:

Lemosin (Harga $)=\left(\frac{45-10}{45-10}\right) * 100 \%=1$

Simental $($ Harga $)=\left(\frac{17-10}{45-10}\right) * 100 \%=0,2$

Bali(Harga) $\quad=\left(\frac{25-10}{45-10}\right) * 100 \%=0,428571$

Perah(Harga) $\quad=\left(\frac{10-10}{45-10}\right) * 100 \%=0$

Brahma(Harga) $=\left(\frac{15-10}{45-10}\right) * 100 \%=0,142857$

Madras (Harga) $=\left(\frac{18-10}{45-10}\right) * 100 \%=0,228571$

Nilai Usia dihitung dengan persamaan 2. Maks(Usia) $=37$ Min(Usia) $=12$

Sehingga:

Lemosin(Usia) $\quad=\left(\frac{37-12}{37-12}\right) * 100 \%=1$

Simental (Usia) $\quad=\left(\frac{24-12}{37-12}\right) * 100 \%=0,48$

Bali (Usia) $\quad=\left(\frac{35-12}{37-12}\right) * 100 \%=0,92$

Perah (Usia) $\quad=\left(\frac{10-12}{37-12}\right) * 100 \%=0,96$

Bramah (Usia) $\quad=\left(\frac{12-12}{37-12}\right) * 100 \%=0$

Madras (Usia) $\quad=\left(\frac{37-12}{37-12}\right) * 100 \%=1$

Nilai Bobot dihitung dengan persamaan 2. $\operatorname{Maks(Bobot)=1100~} \operatorname{Min}($ Bobot $)=250$ 
Sehingga:

$$
\begin{array}{ll}
\text { Lemosin(Bobot) } & =\left(\frac{1100-250}{1100-250}\right) * 100 \%=1 \\
\text { Simental(Bobot) } & =\left(\frac{460-250}{1100-250}\right) * 100 \%=0,247059 \\
\text { Bali(Bobot) } & =\left(\frac{900-250}{1100-250}\right) * 100 \%=0,764706 \\
\text { Perah(Bobot) } & =\left(\frac{250-250}{1100-250}\right) * 100 \%=0 \\
\text { Brahma(Bobot) } & =\left(\frac{310-250}{1100-250}\right) * 100 \%=0,070588 \\
\text { Madras(Bobot) } & =\left(\frac{500-250}{1100-250}\right) * 100 \%=0,294118
\end{array}
$$

Nilai Ukuran dihitung dengan persamaan 2. Maks(Ukuran)=1,5Min(Ukuran)=1

Sehingga:

$$
\begin{array}{ll}
\text { Lemosin(Bobot) } & =\left(\frac{1,5-1}{1,5-1}\right) * 100 \%=1 \\
\text { Simental(Bobot) } & =\left(\frac{1-1}{1,5-1}\right) * 100 \%=0 \\
\text { Bali(Bobot) } & =\left(\frac{1,3-1}{1,5-1}\right) * 100 \%=0,6 \\
\text { Perah(Bobot) } & =\left(\frac{1-1}{1,5-1}\right) * 100 \%=0 \\
\text { Brahma(Bobot) } & =\left(\frac{1,1-1}{1,5-1}\right) * 100 \%=0,2 \\
\text { Madras(Bobot) } & =\left(\frac{1,1-1}{1,5-1}\right) * 100 \%=0,2
\end{array}
$$

Tabel 4. Matriks Perhitungan Nilai Utility Alternatif

\begin{tabular}{|c|c|c|c|c|c|c|}
\hline \multirow{2}{*}{ No } & \multirow{2}{*}{ Alternatif } & \multicolumn{5}{|c|}{ Kriteria } \\
\cline { 3 - 7 } & & Asal & Harga & Usia & Bobot & Ukuran \\
\hline 1 & Lemosin & 1 & 1 & 1 & 1 & 1 \\
\hline 2 & Simental & 0,666667 & 0,2 & 0,48 & 0,247059 & 0 \\
\hline 3 & Bali & 0,333333 & 0,428571 & 0,92 & 0,764706 & 0,6 \\
\hline 4 & Perah & 0 & 0 & 0,96 & 0 & 0 \\
\hline 5 & Brahma & 1 & 0,142857 & 0 & 0,070588 & 0,2 \\
\hline 6 & Madras & 0,333333 & 0,228571 & 1 & 0,294118 & 0,2 \\
\hline
\end{tabular}

d. Menghitung masing-masing nilai alternatif

Menghitung masing-masing nilai alternatif menggunakan rumus persamaan(3) dengan mengkoverensikan antara nilai utiliti dengan nilai normalisasi bobot kriteria sehingga diperoleh nilai terakhir. Perhitungannya adalah sebagai berikut :

Lemosin(Asal) $=1 * 0.1=0.1$

Lemosin(Harga) $=1 * 0.1=0.1$

Lemosin(Usia) $=1 * 0.2=0.2$

Lemosin(Bobot) $=1 * 0.5=0.5$

Lemosin(Ukuran) $1.5 * 0.1=0.1$

Simental(Asal) $=0.6667 * 0.1=0.0667$
Simental(Harga $)=0.2 * 0.1=0.02$

Simental(Usia) $=0.48 * 0.2=0.96$

Simental(Bobot) $=0.2471 * 0.5=0.1235$

Simental(Ukuran) $=0 * 0.1=0$

Bali(Asal) $=0.3333 * 0.1=0.3333$

Bali(Harga $)=0.4286 * 0.1=0.04286$ 


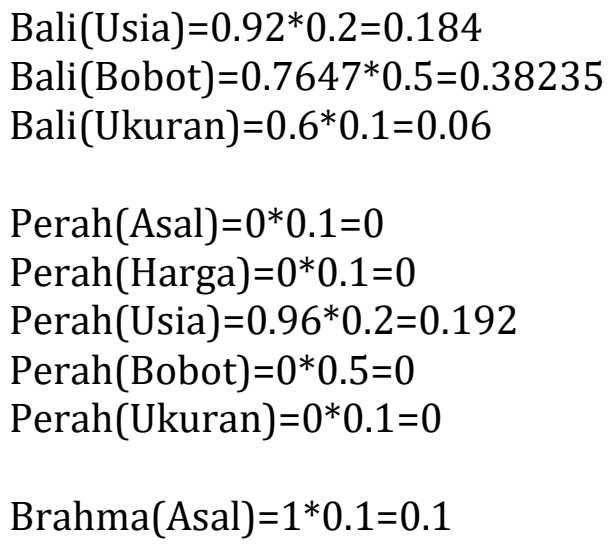

Brahma(Harga $)=0.1429 * 0.1=0.01429$

Brahma(Usia) $=0 * 0.2=0$

Brahma(Bobot $)=0.07059 * 0.5=0.03529$

Brahma(Ukuran) $=0.2 * 0.1=0.02$

$\operatorname{Madras}($ Asal $)=0.3333 * 0.1=0.03333$

Madras(Harga) $=0.22857 * 0.1=0.02286$

Madras(Usia) $=1 * 0.2=0.2$

Madras(Bobot) $=0.29412 * 0.5=0.14706$

Madras(Ukuran) $=0.2 * 0.1=0.2$

Tabel 5. Menentukan nilai akhir menggunakan persamaan (4).

\begin{tabular}{|c|c|c|c|c|c|c|c|}
\hline \multirow{2}{*}{ No } & \multirow{2}{*}{ Alternatif } & \multicolumn{5}{|c|}{ Kriteria } & Nilai \\
\cline { 3 - 7 } & & Asal & Harga & Usia & Bobot & Ukuran & Akhir \\
\hline 1 & Lemosin & 0,1 & 0,1 & 0,2 & 0,5 & 0,1 & 1 \\
\hline 2 & Simental & 0,066667 & 0,02 & 0,096 & 0,123529 & 0 & 0,306196 \\
\hline 3 & Bali & 0,033333 & 0,042857 & 0,184 & 0,382353 & 0,06 & 0,702543 \\
\hline 4 & Perah & 0 & 0 & 0,192 & 0 & 0 & 0,192 \\
\hline 5 & Brahma & 0,1 & 0,014286 & 0 & 0,035294 & 0,02 & 0,16958 \\
\hline 6 & Madras & 0,033333 & 0,022857 & 0,2 & 0,147059 & 0,02 & 0,423249 \\
\hline
\end{tabular}

Dengan demikian alternatif terbaik adalah yang mendominasi alternatif lainnya. Hasil dari perhitungan dengan metode SMART maka diperoleh peringkat yang paling tinggi A1 yaitu jenis Sapi Lemosin.

\section{KESIMPULAN}

Metode SMART telah dapat diterapkan untuk merekomendasikan jenis sapi terbaik untuk peternakan sapi potong dengan mempertimbangkan beberapa kriteria yaitu : Asal, Harga, Usia, Bobot dan Ukuran.

\section{UCAPAN TERIMAKASIH}

Penelitian ini didukung oleh Bapak Antoni Pemilik Peternakan Sapi di Tanah Jawa, Kabupaten Simalungun, Sumatra Utara sebagai objek penelitian.

\section{DAFTAR PUSTAKA}

[1] P. Rakyat and D. I. Kabupaten, "ANALISIS KEUNTUNGAN PETERNAK SAPI POTONG BERBASIS PETERNAKAN RAKYAT DI KABUPATEN BONE Profit Analysis of Cattle Farms Based on Rural Farm in Bone Regency Hastang, Aslina Asnawi," no. 2, pp. 240-252.

[2] D. Novianti, I. F. Astuti, and D. M. Khairina, "Sistem Pendukung Keputusan Berbasis Web Untuk Pemilihan Café Menggunakan Metode Smart ( Simple Multi-Attribute Rating Technique ) ( Studi Kasus : Kota Samarinda )," Seminar Sains dan Teknologi FMIPA Unmul, pp. 1-5, 2016.

[3] Pratiwi, "Penerapan Smart System Sebagai Metode Pengukuran Kinerja Perusahaan (Studi Kasus Pada Ukm Hentoro Leather)," Universitas Gunadarma, no. 1, pp. 1-5, 2014.

[4] D. S. Sinaga et al., "Analisa Metode SMART Dalam Merekomendasikan Peserta UKK Jurusan TKJ," no. x, pp. 1-10, 2012.

[5] Yeni Kustiyahningsih and N. Syafa'ah, "Sistem Pendukung Keputusan Untuk Menentukan Jurusan Pada Siswa Sma Menggunakan Metode Knn Dan Smart," Jsii, vol. 1, no. 1, pp. 19-28, 
2014.

[6] E. Yulianti, "Jurnal Momentum ISSN : 1693-752X SISTEM PENDUKUNG KEPUTUSANPEMILIHAN MOBIL DENGAN METODA SIMPLE MULTY ATTRIBUTE RATING ( SMART ) Jurnal Momentum ISSN : 1693-752X," Jurnal Momentum, vol. 17, no. 1, pp. 55-59, 2015.

[7] A. S. Honggowibowo, "Sistem Pendukung Keputusan Penerimaan Calon Teknologi Adisutjipto Menggunakan Simple Multi Attribute Rating Technique," Jurnal angkasa, vol. VII, no. 2, pp. 31-38, 2015.

[8] T. Imandasari, A. Wanto, and A. P. Windarto, "Analisis Pengambilan Keputusan Dalam Menentukan Mahasiswa PKL Menggunakan Metode PROMETHEE," Jurnal Riset Komputer (JURIKOM), vol. 5, no. 3, pp. 234-239, 2018.

[9] A. Wanto and E. Kurniawan, "Seleksi Penerimaan Asisten Laboratorium Menggunakan Algoritma AHP Pada AMIK-STIKOM Tunas Bangsa Pematangsiantar," Jurnal Informatika dan Komputer (JIKO), vol. 3, no. 1, pp. 11-18, 2018.

[10] A. Wanto and H. Damanik, "Analisis Penerapan Sistem Pendukung Keputusan Terhadap Seleksi Penerima Beasiswa BBM (Bantuan Belajar Mahasiswa) Pada Perguruan Tinggi Menggunakan Metode Simple Additive Weighting (SAW) (Studi Kasus : AMIK Tunas Bangsa Pematangsiantar)," in Seminar Nasional Rekayasa (SNTR) II, 2015, no. 2, pp. 323-333.

[11] M. Widyasuti, A. Wanto, D. Hartama, and E. Purwanto, "Rekomendasi Penjualan Aksesoris Handphone Menggunakan Metode Analitycal Hierarchy Process (AHP)," Konferensi Nasional Teknologi Informasi dan Komputer, vol. 1, no. 1, pp. 27-32, 2017.

[12] S. Sundari, A. Wanto, Saifullah, and I. Gunawan, "Sistem Pendukung Keputusan Dengan Menggunakan Metode Electre Dalam Merekomendasikan Dosen Berprestasi Bidang Ilmu Komputer (Study Kasus di AMIK \& STIKOM Tunas Bangsa)," in Seminar Nasional Multi Disiplin Ilmu, 2017, pp. 1-6.

[13] R. A. Hutasoit, S. Solikhun, and A. Wanto, "Analisa Pemilihan Barista dengan Menggunakan Metode TOPSIS (Studi Kasus: Mo Coffee)," KOMIK (Konferensi Nasional Teknologi Informasi dan Komputer), vol. 2, no. 1, pp. 256-262, 2018.

[14] N. Rofiqo, A. P. Windarto, and A. Wanto, "Penerapan Metode VIKOR Pada Faktor Penyebab Rendahnya Minat Mahasiswa Dalam Menulis Artikel Ilmiah," Seminar Nasional Sains \& Teknologi Informasi (SENSASI), vol. 1, no. 1, pp. 228-237, 2018.

[15] L. P. Purba, A. P. Windarto, and A. Wanto, "Faktor Terbesar Rendahnya Minat Ber-KB (Keluarga Berencana) dengan Metode ELECTRE II," Seminar Nasional Sains \& Teknologi Informasi (SENSASI), vol. 1, no. 1, pp. 369-374, 2018.

[16] M. Masitha, D. Hartama, and A. Wanto, "Analisa Metode (AHP) pada Pembelian Sepatu Sekolah Berdasarkan Konsumen," Seminar Nasional Sains \& Teknologi Informasi (SENSASI), vol. 1, no. 1, pp. 338-342, 2018.

[17] S. R. Ningsih, D. Hartama, A. Wanto, I. Parlina, and Solikhun, "Penerapan Sistem Pendukung Keputusan Pada Pemilihan Objek Wisata di Simalungun," in Seminar Nasional Teknologi Komputer \& Sains (SAINTEKS), 2019, pp. 731-735.

[18] S. Sundari, S. M. Sinaga, I. S. Damanik, and A. Wanto, "Sistem Pendukung Keputusan Pemilihan Peserta Olimpiade Matematika SMA Swasta Teladan Pematangsiantar Dengan Metode Electre," in Seminar Nasional Teknologi Komputer \& Sains (SAINTEKS), 2019, pp. 793-799.

[19] N. Sesnika, D. Andreswari, and R. Efendi, "Aplikasi Sistem Pendukung Keputusan Pemilihan Gedung Serba Guna Di Kota Bengkulu Dengan Menggunakan Metode Smart Berbasis Android," Jurnal Rekursif, vol. 4, no. 1, pp. 30-44, 2016. 